\title{
Design of gas concentration measurement and monitoring system for biogas power plant
}

\author{
Iswanto $^{1}$, Alfian Ma'arif ${ }^{2}$, Bilah Kebenaran $^{3}$, Prisma Megantoro ${ }^{4}$ \\ ${ }^{1,3}$ Department of Electrical Engineering, Universitas Muhammadiyah Yogyakarta, Indonesia \\ ${ }^{2}$ Department of Electrical Engineering, Universitas Ahmad Dahlan, Indonesia \\ ${ }^{4}$ Faculty of Science and Technology, Universitas Airlangga, Indonesia
}

\begin{tabular}{l}
\hline Article Info \\
\hline Article history: \\
Received May 5, 2020 \\
Revised Dec 12, 2020 \\
Accepted Jan 11, 2021
\end{tabular}

Keywords:

Biogas plant

Microcontroller

Sensor characterization

\begin{abstract}
Biogas is a gas obtained from the breakdown of organic matter (such as animal waste, human waste, and plants) by methanogenic bacteria in an oxygen-free (anaerobic) state. The biogas produced mainly consists of 50$70 \%$ methane, 30-40\% carbon dioxide, and other gases in small amounts. The gas produced has a different composition depending on the type of animal that produces it. It is challenging to obtain biogas concentration data because the monitoring equipment is currently minimal. Therefore, this research discusses how to make a monitoring system for biogas reactors. Sensors are installed in the digester tank and storage tank. The installed sensors are the MQ-4 sensor to detect methane gas (CH4), MG-811 sensor to detect carbon dioxide (CO2) gas, MQ-136 sensor to detect sulfide acid gas (H2S), and thermocouple type-K to detect temperature. The sensor will send a signal to the control unit in Arduino Mega 2560, then processed and displayed on the liquid crystal display (LCD). The sensor calculation results' accuracy is not much different from the reference based on the sensor readings. The sensor deviation standard is 5.0, indicating that the sensor is in precision. The sensor's linearity of MQ-4 is $0.7 \%$, the MG- 811 is $0.17 \%$, the MQ-136 is $0.29 \%$, and the Type-K Thermocouple is $1.19 \%$. The installed sensor can be used to monitor gas concentration and temperature in a biogas reactor.
\end{abstract}

This is an open access article under the CC BY-SA license.

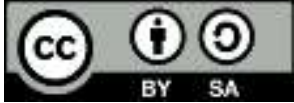

\section{Corresponding Author:}

Iswanto

Department of Electrical Engineering

Universitas Muhammadiyah Yogyakarta

Email: iswanto_te@umy.ac.id

\section{INTRODUCTION}

Biogas is a gas mixture of methane $(\mathrm{CH} 4)$, carbon dioxide $(\mathrm{CO} 2)$, and other gases obtained from the breakdown of organic matter (such as animal waste, human waste, and plants) by methanogenic bacteria. Organic materials needed are stored in biodigesters to produce biogas. The process of decomposition of organic matter occurs anaerobically (without oxygen). Biogas is formed on days 4-5 after the biodigester is fully charged and reaches its peak on days 20-25. The biogas produced mainly consists of 50-70\% methane, $30-40 \%$ carbon dioxide, and other gases in small amounts.

Biogas is produced when organic materials break down to form compounds in an oxygen-free (anaerobic) state. Anaerobic fermentation is common in wet soils. The fermentation process is the decomposition of organic materials with the help of microorganisms. Anaerobic fermentation can produce a gas containing at least $50 \%$ methane. This gas is called biogas. Biogas can be produced from the 
fermentation of organic waste such as market waste, foliage, and animal waste from cattle, pigs, goats, or others. The gas produced has a different composition depending on the type of animal that produces it.

Some previous researchers have researched measurements with GAS sensors. De Lima investigated a single DFB laser controller for the simultaneous detection of several gases in near-infrared. The initial version of the system was implemented using a PIC18F4550 microcontroller, oscillator, D/A converter, solid-state relay, DFB laser, and additional circuits with the development of one DFB laser controller for simultaneous detection of several gases in near-infrared [1]. Sasidharan investigated the safety warning system of a vehicle cabin. The reduced oxygen level in the vehicle cabin will cause drowsiness, fatigue which causes many road accidents that occur every year; even the Exhaust Gas Suicide occurs mainly because of the poisonous gas that enters the vehicle cabin [2]. The reliability test of the forest fire detection system using wireless sensor networks and the OpenMTC communication platform was investigated by Herutomo [3]. Machine to machine communication (M2M) [4]-[6] systems has begun to gain real-world momentum with the introduction of the internet and cellular technology. Several works in this system have emerged to use this integrated system into many different vertical solutions and try to tie one solution platform for many monolithic systems. The highly selective MEMS transducer for hydrogen sensing based on voltage modification on palladium thin-films was investigated by [7]. Capacitive bimorph aluminum/palladium-based MEMS transducers were developed and integrated configured as clamp beams, carrying out rapid and highly selective hydrogen detection. Gandhi investigated a field-applied laser spectroscopy system developed with Raspberry Pi for the detection of CO2 in $2003.5 \mathrm{~nm}$. CO2 sensors can be used in real-time, non-invasive, compact, and field use tunable laser diode (TDLAS) [8].

Suganya investigated a smart vehicle monitoring system for the detection of air pollution using WSN. The research focused on measuring gas levels from air contamination around cities, reducing human labor, and increasing the sender and receiver's flexibility as a whole [9]. Shi investigated the detection of hazardous gas development of a four-rotor UAV system. Under the framework of the embedded operating system UC/OS, to replace staff workers, this UAV is used to detect hazardous gases through all types of sensors [10]. Gangopadhyay investigated the wireless framework for environmental monitoring and instant response warnings. Internet of things (IoT) is one of the leading technological trends used to monitor natural and human-made resources to assist in predicting and detecting emergency events such as floods, fires, gas and water leaks that can cause intimidation of human life [11]. Groenesteijn investigated a single-chip mass flow controller with an integrated Coriolis flow sensor and proportional control valve. The system can control the mass flow of up to $70 \mathrm{mgh}$ of nitrogen gas at a pressure applied to 500 milibar [12]. Dutta examined the direct interface comparison and the ADC-based system for gas identification using E-Nose. We studied microcontroller-based online gas discrimination by E-Nose using DIC and compared it with ADC results. Equivalent results were observed for both cases with an accuracy of up to 97\% [13].

Keshamoni proposed smart gas level monitoring, reservation of gas leak detectors through IoT. The research was made to create awareness about reducing the gas's weight in the container and ordering gas using IoT [14]. Somov proposed an explosion risk estimation of gas mixtures by measuring oxidation heat in catalytic sensors. A mixture of flammable gas and flammable vapor exists in many industrial operating environments [15]. Notifying and checking vehicle emissions and vehicle engine temperatures investigated by Kamalakar. This proposed system helps to remind vehicle owners of some of these things: their carbon dioxide emissions; LPG gas leak if the vehicle is gas-operated; the engine temperature to avoid vehicle failure due to overheating of the vehicle engine [16]. The electronic nose to classify beef and pork using Naïve Bayes was investigated by Wijaya. The electronic system is made using an Arduino microcontroller and sensor array consisting of eight Semiconductor Metal-Oxide gas sensors [17]. Bakar investigated electronic nose cleaning techniques for limited space applications. Analog to digital converter (ADC) readings of the gas sensor response are measured and defined into parts per million (ppm) and percentage levels [18].

Obtaining the gas concentration data produced by biogas is challenging because its monitoring equipment is currently minimal. The measurement process is still affected by human error so that it is necessary to develop technological breakthroughs to meet the needs of gas concentration data in biogas. An attempt to overcome the problems is by making measuring devices that can display gas concentrations using a microcontroller suitable for the system's design. A microcontroller has broad instrument applications but can be explicitly used.

The research aimed to make a monitoring system for biogas reactors. Gas sensors and temperature sensors were installed in the reactor. The data measured by the sensor were processed by Arduino Mega 2560, then displayed on the LCD screen. The arduino board was very reliable for measuring and controlling instrument applications [19]. The results displayed on the LCD screen were recorded and analyzed by processing data based on the static characteristics of the measuring instrument. By such a monitoring system, it is expected that monitoring the concentration of gas produced by biogas is more manageable. 
The paper will be organized as follows. The first section is the introduction. The second one is the research method, which discusses the system workflow and implementation design. In section three, the implementation will be explained in detail, which contains the accuracy and precision testing method. The fourth section is the result and discussions, while the last section is the conclusion.

\section{RESEARCH METHOD}

\subsection{System workflow}

Two tanks provided as biogas reactors were a digester tank and a storage tank. A digester tank was a tank where the reaction takes place, while a storage tank was a tank to store the gas produced in the digester tank. The gas produced in the digester tank would be flowed using a connecting pipe installed with a valve between the two tanks.

Four sensors were installed in each tank. The sensors contained in the digester tank worked to monitor the biogas' concentration and the temperature produced by the biogas reactor, while the sensor mounted on the storage tank was to see any leakage or gas when the gas flowed from the digester tank. Figure 1 displays the P\&ID [20]-[23] flow diagram of the biogas reactor monitoring process.

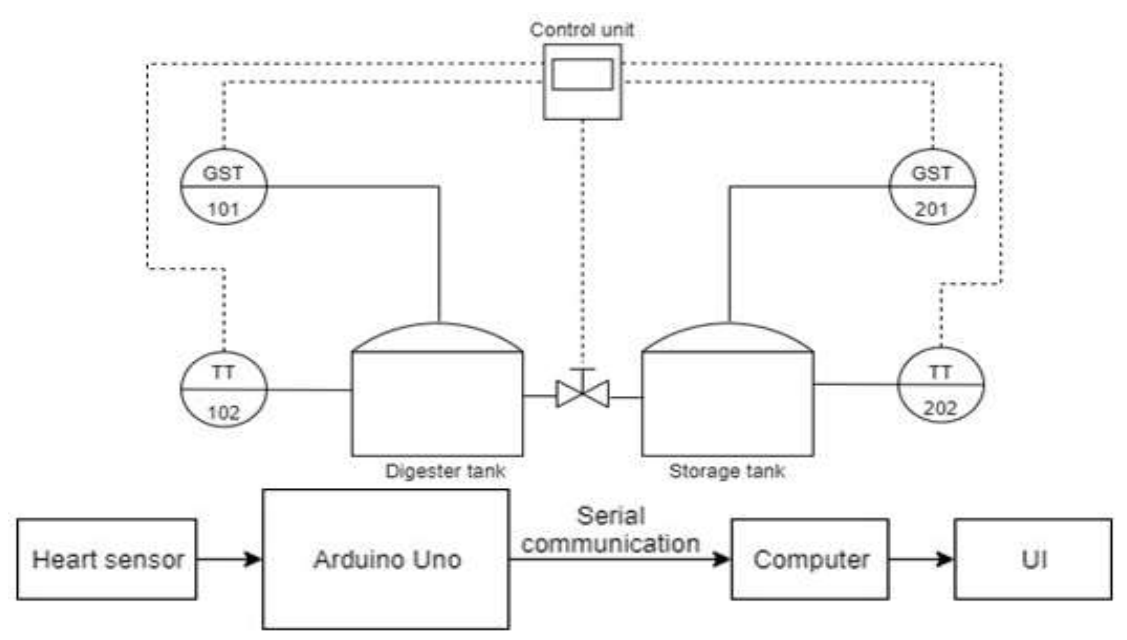

Figure 1. P\&ID of biogas system

The installed sensors were the MQ-4 sensor to detect methane gas (CH4), MG-811 sensor to detect carbon dioxide (CO2) gas, MQ-136 sensor to detect sulfide acid gas (H2S), and Thermocouple Type-K to detect the temperature. The sensors sent a signal to the control unit in Arduino Mega 2560 [24]-[25], and then it would be processed and displayed on LCD.

\subsection{System implementation design}

The devising hardware and software were conducted in parallel. The hardware designing started with depicting the circuit schematic design using the EAGLE software, then printed it on the PCB. The components were placed on the PCB and soldered after printing.

The software making started with making a program on each sensor and for the LCD Arduino software. After ensuring all programs were correct, the program was integrated and tested. Finally, the program was uploaded to the hardware that had been assembled.

\section{IMPLEMENTATION}

\subsection{Accuracy calculation}

The accuracy of a measuring instrument is essential in providing reading results. Measurement accuracy is the level of closeness of the measurement of the quantity to the actual value. This magnitude shows the number of deviations that occur in a measuring instrument or measurement system. There are several ways to express accuracy. 
1. In the form of measurement variables

For example, a thermometer with a scale of $0^{\circ} \mathrm{F}-100^{\circ} \mathrm{F}$ is said to have an accuracy of $1^{\circ} \mathrm{F}$. If the thermometer shows a temperature of $60^{\circ} \mathrm{F}$, the actual temperature ranges from $59^{\circ} \mathrm{F}-61^{\circ} \mathrm{F}$.

2. In percentages span

A pressure transmitter has a range of $100-400$ psi and an accuracy of $0.5 \%$ span. It means that each signal coming out of the transmitter can deviate to $0.5 \%$ x $300 \mathrm{psi}=1.5 \mathrm{psi}$. For example, if the transmitter reading is $200 \mathrm{psi}$, the actual pressure ranges between $198.5 \mathrm{psi}$ and $201.5 \mathrm{psi}$.

3. In the percentage of the maximum scale

The term maximum scale is usually called full scale (FS). A voltmeter said to have an accuracy of $1 \%$ FS means that if the meter is placed on a maximum reading scale of 200 volts, the accuracy in that range is \pm 2 volts.

4. In the percentage of readings,

A transmitter level is said to have an accuracy of $0.5 \%$ output. If the transmitter shows a $40 \mathrm{~cm}$ signal in transmitter with a $0-100 \mathrm{~cm}$ range, the actual level ranges from 39.8 to $40.2 \mathrm{~cm}$.

\subsection{Precision calculation}

Precision is the ability to produce the same value from the measurement results made repeatedly and identically (measuring points and time are relatively the same). The precision shows the level of reliability of the measurement data obtained. The smaller the difference in repeated measures, the better the measuring instrument's performance; it can be seen from the standard deviation obtained from the measurement. Standard deviation is a statistical value utilized to determine how the sample data is distributed, as well as how close an individual's point can be to the mean (average value). If the spread of the average value is very large, the value of $\square \square$ will be enormous and vice versa. Serves to find out whether the data samples taken represent the population. A good precision will give a small standard deviation. The following formulary is the formula to calculate the standard deviation.

\section{RESULT AND DISCUSSION}

\subsection{Accuracy analysis}

In determining the measuring instrument's accuracy, the sensor readings of MQ-4, MG-811, and MQ-136 results are compared with secondary data consisting of clean air composition. Meanwhile, Thermocouple Type-K reading results will be compared with another measuring device, namely NTC. Figure 2 shows the comparison between the MQ-4 reading sensor and the clean air composition. The sensor readings are always greater than the reference value, both in the digester tank and the storage tank. The sensor reading value increased in the second experiment, thereby causing a greater difference from the reference value. The rust on the sensor causes an increase in the MQ-4 sensor graph. The rust is caused by the placement of sensors in the tank not needed by the protector so that the sensor is exposed to the gas produced from biogas. In experiment three, reading the sensor graph on the digester tank improves the reduction because the sensor in the digester tank has been replaced with a new device, while the storage tank continues to increase.

Figure 3 shows that the results of MG-811 sensor readings in the digester tank always increase. The biggest increase is in the third experiment caused a large difference from the reference. Rising graphs are caused by rust on the MG-811 sensor. Because there was no sensor change, the third graph increased drastically, while the MG-811 sensor readings in the storage tank are lower than the reference. The resulting value is almost constant from the first to the third try. The conditions in the storage tank are not exposed to gas produced too long, so the sensor is more durable in the storage tank.

Figure 4 depicts the increase of MQ-136 sensor readings in the digester tank, promoting a large difference from the reference. Similar to MQ-4 and MG-811 reading results, the MQ-136 sensor also rusts; hence the graph shows an increase in the second experiment. Since there is no turnover sensor, the transition sensor testing increases with a reasonably large graph. The sensor readings in the storage tank are constant from the first three experiments, but the value is higher than the reference.

Figure 5 shows the comparison between a K-type Thermocouple tank and a storage NTC. Sensor readings are always greater than the reference value, both in the digester tank and the storage tank. The sensor reading value increased in the second experiment, thereby causing a greater difference than the reference value. The corrosion on the sensor causes an increase in the NTC sensor graph. Rust is caused by placing the sensor in a tank that is not needed by the protector so that the sensor is exposed to gas produced from biogas. 


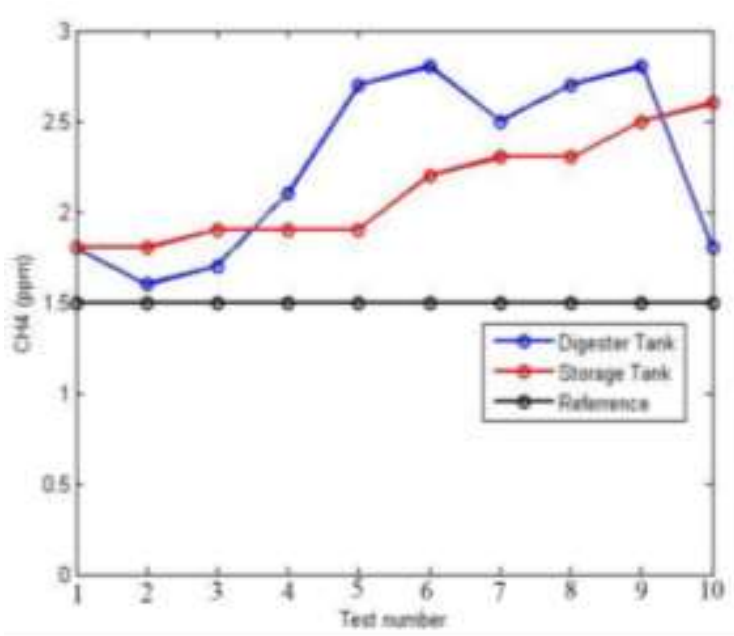

Figure 2. Comparison between MQ-4 with clean air

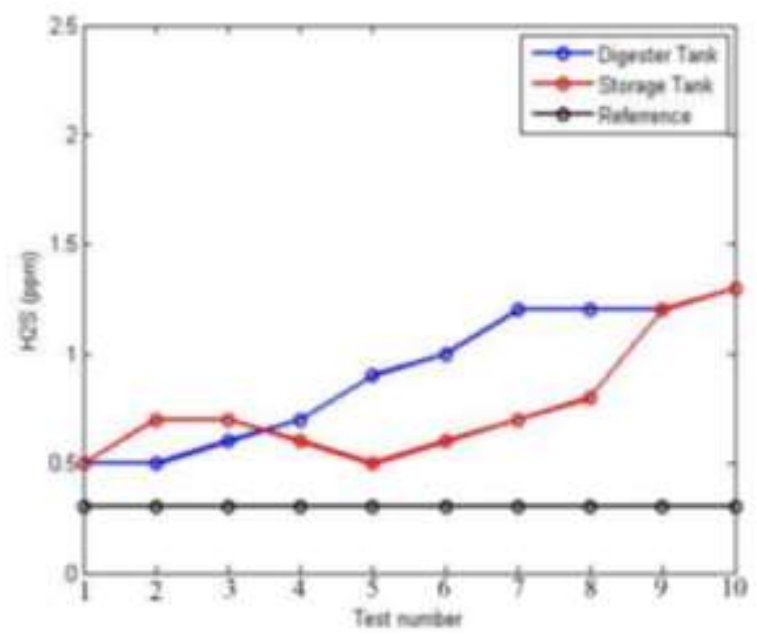

Figure 4. Comparison between MQ-136 with clean air

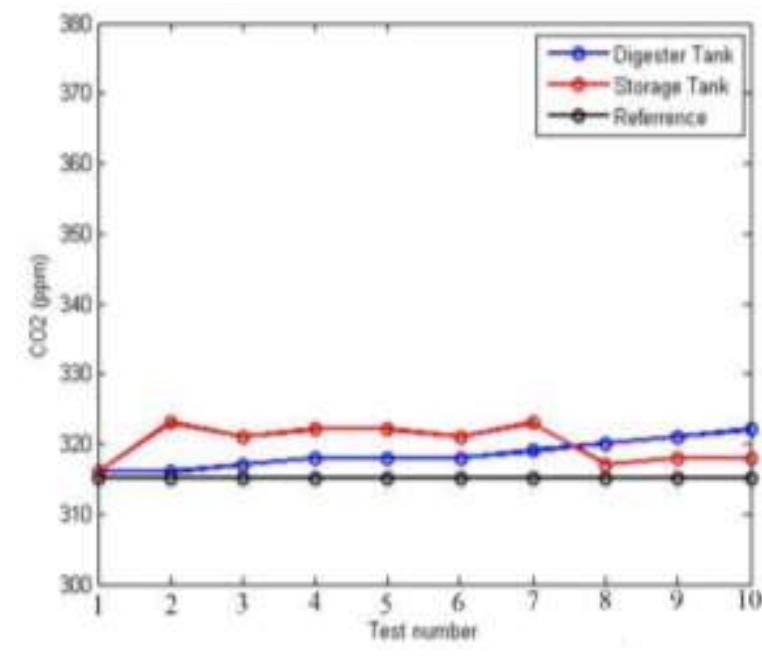

Figure 3. Comparison between MG-811 with clean air

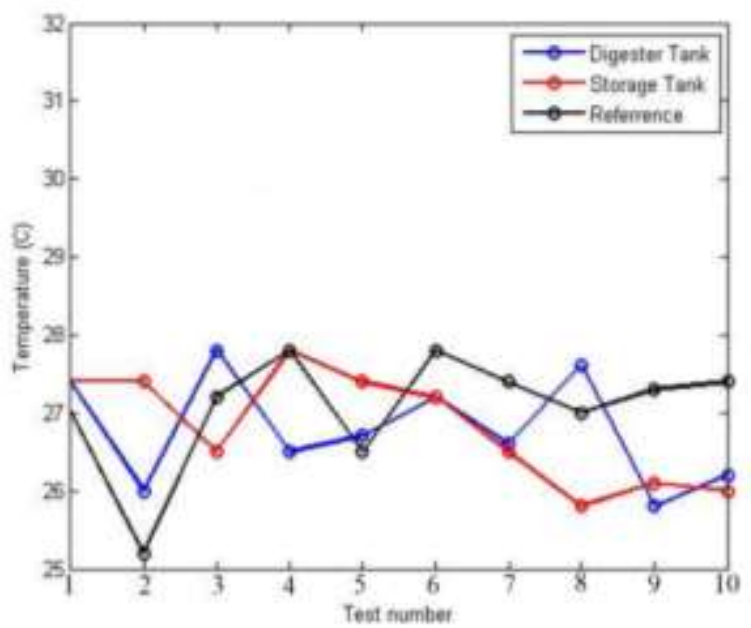

Figure 5. Comparison between Thermocouple type-K with NTC

\subsection{Precision analysis}

The number of precisions is calculated using the standard deviation. Figure 6 displays the standard deviation of the storage tank, and Figure 7 displays the standard deviation of the digester tank. Figures 6 and 7 show that the MQ-4 and MG-811 sensors' standard deviations have increased in the second experiment but decreased in the third experiment. The MQ-136's standard deviation in the digester tank is different from that of the storage tank in which the graph shows an increase and a decrease, respectively. The standard deviation of the Type-K Thermocouples from the first to the third experiments tends to be constant. In the second experiment, almost all sensors experienced an increase in the standard deviation due to the sensor's rust that affects the reading results. Before the third experiment, the rusted sensor had been cleaned so that its precision remained within the allowed limits. The MQ-4 sensor and Thermocouple Type-K in the digester tank are replaced with a new one because the sensor's rust is difficult to clean. However, Figure 6 and 7 show that standard deviations of all sensors in the two tanks are 5.0, showing that those sensors are still precise. 


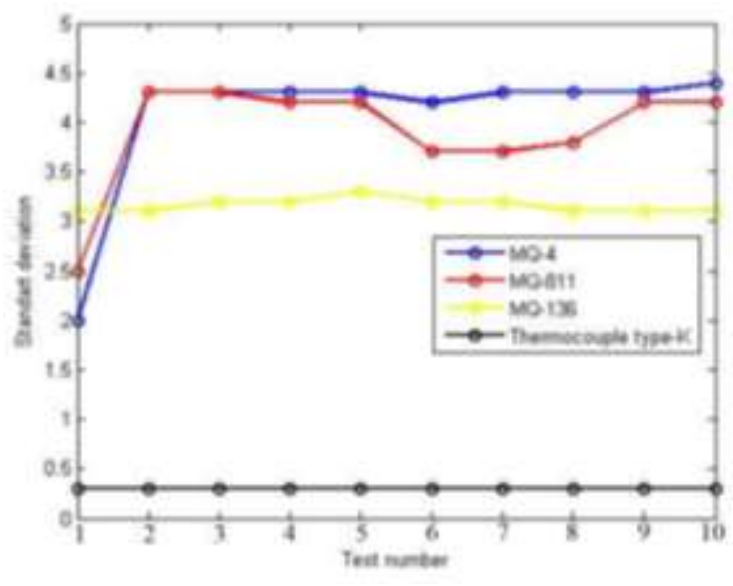

Figure 6. Standard deviation of Digester Tank

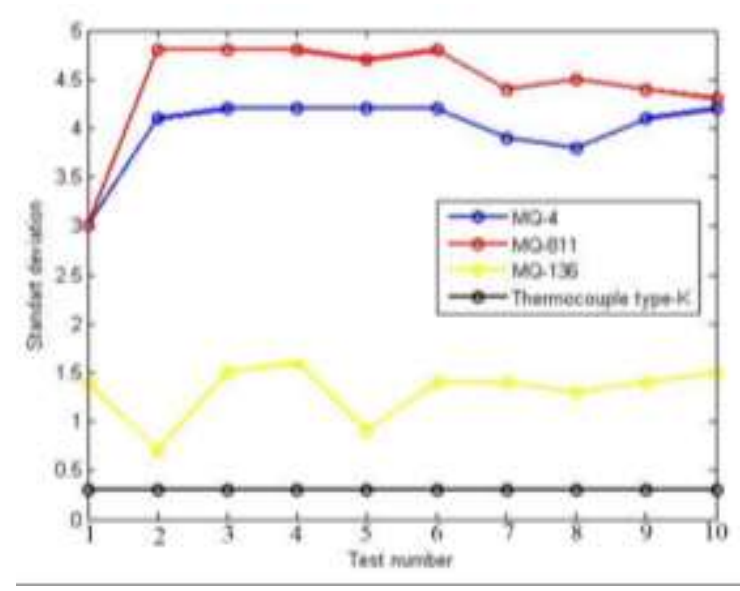

Figure 7. Standard deviation of Storage Tank

\section{CONCLUSION}

Sensor accuracy calculation results are not much different from the reference. Sensor deviation standards are 5.0, indicating the sensor is precise. The installed sensor can be used to monitor gas concentration and temperature in a biogas reactor.

\section{REFERENCES}

[1] R. A. de Lima and E. Fontana, "Single controller of DFB lasers for the simultaneous detection of multiple gases in the near infrared," in 2015 SBMO/IEEE MTT-S International Microwave and Optoelectronics Conference (IMOC), 2015, vol. 2015-December, pp. 1-4. doi: 10.1109/IMOC.2015.7369181

[2] S. Sasidharan and V. Kanagarajan, "Vehicle cabin safety alert system," in 2015 International Conference on Computer Communication and Informatics (ICCCI), 2015, pp. 1-4. doi: 10.1109/ICCCI.2015.7218155

[3] A. Herutomo, M. Abdurohman, N. A. Suwastika, S. Prabowo, and C. W. Wijiutomo, "Forest fire detection system reliability test using wireless sensor network and OpenMTC communication platform," in 2015 3rd International Conference on Information and Communication Technology (ICoICT), 2015, pp. 87-91.

[4] A. Ghasempour, "Optimum number of aggregators based on power consumption, cost, and network lifetime in advanced metering infrastructure architecture for Smart Grid Internet of Things," in 2016 13th IEEE Annual Consumer Communications \& Networking Conference (CCNC), 2016, pp. 295-296.

[5] A. Ghasempour and T. K. Moon, "Optimizing the Number of Collectors in Machine-to-Machine Advanced Metering Infrastructure Architecture for Internet of Things-Based Smart Grid," in 2016 IEEE Green Technologies Conference (GreenTech), 2016, vol. 2016-April, pp. 51-55.

[6] A. Ghasempour, "Internet of Things in Smart Grid: Architecture, Applications, Services, Key Technologies, and Challenges," Inventions, vol. 4, no. 1, p. 22, Mar. 2019.

[7] T. Walewyns, C. Emmerechts, P. Gerard, N. Andre, and L. A. Francis, "A highly selective MEMS transducer for hydrogen sensing based on stress modification in palladium thin films," in 2015 IEEE SENSORS, 2015, pp. 1-4. doi: 10.1109/ICSENS.2015.7370404

[8] V. Gandhi, S. Heda, R. Anand, Zarin A S, A. Upadhyay, and A. L. Chakraborty, "A Raspberry Pi-based fielddeployable tunable diode laser spectroscopy system for the detection of $\mathrm{CO} 2$ at $2003.5 \mathrm{~nm}$," in 2015 International Conference on Microwave and Photonics (ICMAP), 2015, pp. 1-2.

[9] E. Suganya and S. Vijayashaarathi, "Smart vehicle monitoring system for air pollution detection using Wsn," in 2016 International Conference on Communication and Signal Processing (ICCSP), 2016, pp. 0719-0722.

[10] L. Shi, X. Wang, T. Zhang, C. Hu, K. Luo, and B. Bai, "Hazardous gas detection four-rotor UAV system development," in 2016 IEEE International Conference on Mechatronics and Automation, 2016, pp. 2461-2465.

[11] S. Gangopadhyay and M. K. Mondal, "A wireless framework for environmental monitoring and instant response alert," in 2016 International Conference on Microelectronics, Computing and Communications (MicroCom), 2016, pp. 1-6.

[12] J. Groenesteijn, D. Alveringh, M. S. Groen, R. J. Wiegerink, and J. C. Lotters, "Single-chip mass flow controller with integrated coriolis flow sensor and proportional control valve," in 2016 IEEE 29th International Conference on Micro Electro Mechanical Systems (MEMS), 2016, vol. 2016-Febru, no. January, pp. 788-791.

[13] L. Dutta, A. Hazarika, and M. Bhuyan, "Comparison of direct interfacing and ADC based system for gas identification using E-Nose," in 2016 International Conference on Accessibility to Digital World (ICADW), 2016, pp. 15-19.

[14] K. Keshamoni and S. Hemanth, "Smart Gas Level Monitoring, Booking \&amp; Gas Leakage Detector over IoT," in 2017 IEEE 7th International Advance Computing Conference (IACC), 2017, pp. 330-332. 
[15] A. Somov, A. Karelin, A. Baranov, and S. Mironov, "Estimation of a Gas Mixture Explosion Risk by Measuring the Oxidation Heat Within a Catalytic Sensor," IEEE Trans. Ind. Electron., vol. 64, no. 12, pp. 9691-9698, Dec. 2017.

[16] S. S. Kamalakar and M. S. Vanjale, "Notifying and inspecting vehicle emission and temperature of vehicle engine," in 2017 Conference on Emerging Devices and Smart Systems (ICEDSS), 2017, no. March, pp. 5-8.

[17] D. R. Wijaya, R. Sarno, and A. F. Daiva, "Electronic nose for classifying beef and pork using Naïve Bayes," in 2017 International Seminar on Sensors, Instrumentation, Measurement and Metrology (ISSIMM), 2017, vol. 2017Janua, pp. 104-108.

[18] M. A. A. Bakar et al., "Electronic nose purging technique for confined space application," in 2017 IEEE 13th International Colloquium on Signal Processing \& its Applications (CSPA), 2017, no. March, pp. 185-189.

[19] N. H. Wijaya, A. Agtesa, G. D. B. Silva, V. Dhinakaran, and M. Usman, "Simulation of Vetilligo Therapy Equipment," J. Robot. Control, vol. 1, no. 4, pp. 124-128, 2020.

[20] A. Juliano, A. H. Hendrawan, and R. Ritzkal, "Information System Prototyping of Strawberry Maturity Stages using Arduino Uno and TCS3200," J. Robot. Control, vol. 1, no. 3, pp. 86-91, 2020.

[21] A. A. Rafiq, W. N. Rohman, and S. D. Riyanto, "Development of a Simple and Low-cost Smartphone Gimbal with MPU-6050 Sensor," J. Robot. Control, vol. 1, no. 4, pp. 136-140, 2020.

[22] A. Latif, K. Shankar, and P. T. Nguyen, "Legged Fire Fighter Robot Movement Using PID," J. Robot. Control, vol. 1, no. 1, pp. 15-19, 2020.

[23] B. A. Saputra, E. P. Hidayat, and A. Z. Arfianto, "Internet of Things-Based Steam Pump Motor Protection Due to Voltage Unbalance," J. Robot. Control, vol. 1, no. 2, pp. 64-69, 2020.

[24] M. W. Hariyanto, A. H. Hendrawan, and R. Ritzkal, "Monitoring the Environmental Temperature of the Arduino Assistance Engineering Faculty Using Telegram," J. Robot. Control, vol. 1, no. 3, pp. 96-101, 2020.

[25] J. Juhariansyah, R. Ritzkal, and A. H. Hendrawan, "Design Of An Automatic Bell Warning System For Prayer Times In A Net Centric Computing Lab," J. Robot. Control, vol. 1, no. 3, pp. 92-95, 2020.

\section{BIOGRAPHIES OF AUTHORS}

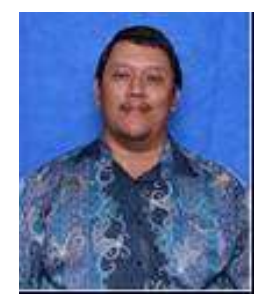

Iswanto was born in Sleman, Yogyakarta, Indonesia, in 1981. He received the B.S degree, M.Eng degree and Doctoral degree from Universitas Gadjah Mada, Yogyakarta, Indonesia in 2007, 2009, and 2018. He has been a Lecturer and Researcher in the Electrical Engineering Department at Universitas Muhammadiyah Yogyakarta since 2010. His current research is focused on IoT, formation control, path planning and Control UAV.

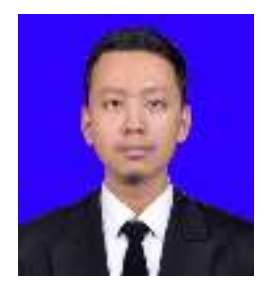

Alfian Ma'arif was born in Klaten, central java, Indonesia, in 1991. He received a bachelor's degree in the Department of Electrical Engineering, Universitas Islam Indonesia, in 2014. He received the Master of Engineering in Department of Electrical Engineering, Universitas Gadjah Mada, Indonesia in 2017. Currently, he was a lecturer in the Department of Electrical Engineering, Universitas Ahmad Dahlan. His research interest includes control system design, computer programming, robotic and microcontroller system.

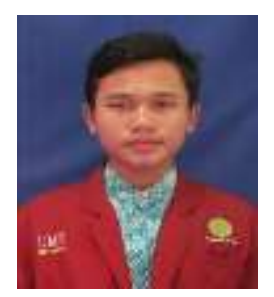

Bilah Kebenaran was born in Cirebon, West Java, Indonesia. He received the B.S degree from Universitas Muhammadiyah Yogyakarta, Yogyakarta, Indonesia in 2016. His current research is focused on renewable energy and internet of things.

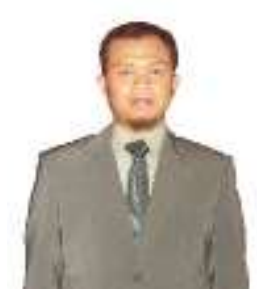

Prisma Megantoro was born in Sukoharjo, Central Java, Indonesia, in 1991. He received the B.S degree and M.Eng degree from Universitas Gadjah Mada, Yogyakarta, Indonesia in 2014 and 2018. His current research is focused on solar photovoltaic technology, embedded system, and internet of things. 